\title{
Integrating Professional Communication \\ Into Civil and Environmental Engineering Curricula
}

\author{
D. S. Kukich, S. A. Bernhardt, P. T. Imhoff, M. J. Chajes, and M. Pearlman \\ University of Delaware
}

\author{
D. M. O'Neill \\ Delaware Department of Transportation
}

\begin{abstract}
The University of Delaware's Department of Civil and Environmental Engineering has recently undergone major revisions to its two curricula. One important goal of both new curricula is to place a greater emphasis on professional communication. This paper first describes how faculty from engineering and English worked together to incorporate written, oral, and graphical communication throughout the new curricula. In addition, it describes the design and implementation of a case-based technical communication course, wherein students work with actual civil engineering documents and work practices.
\end{abstract}

An important goal of the new curricula is to coordinate instruction in communication skills throughout the four-year programs, so that students become increasingly skilled communicators in both formal and everyday work contexts. Partnering with technical professionals in the development of the integrated curricula will enable university faculty to more accurately simulate the work experience and will facilitate students' transition from the academic environment to the professional workplace. The paper details how changes in existing courses have enabled communication skills to be taught and practiced during all four years of the curricula.

The case-based course is structured around a set of actual materials from the Delaware Department of Transportation (DelDOT) that was developed to inform the public about the upgrade of Interstate 95 through Wilmington. Students are working in project teams to develop their own communication strategies and solutions based on documents from the actual project and then comparing their team solutions to those actually used by DelDOT during the project. The course was developed as a traditional classroom course, but with a strong component of virtual interaction through the Web-CT course management system to allow computer-mediated team and full-class communication, access to a library of case documentation, connections to supporting research resources, online meetings in real time, online document development and review, and instructor interaction. 


\section{Background}

In 2000, the Accreditation Board for Engineering and Technology (ABET) established Engineering Criteria 2000 (more commonly known as ABET 2000) ${ }^{1}$. ABET 2000 represents a major change from previous accreditation criteria in that (1) it offers engineering programs more flexibility in determining how to meet objectives and (2) it focuses on outcomes rather than simply on input.

One of the outcomes that has received increased emphasis is improved communication skills. According to Criterion 3, "Program Outcomes and Assessment," basic-level engineering programs must demonstrate that their graduates have abilities and knowledge in eleven areas, including "an ability to communicate effectively." Criteria for advanced-level programs are the same as for basic level programs with the addition of "one year of study beyond the basic level and an engineering project or research activity resulting in a report that demonstrates both mastery of the subject matter and a high level of communication skills."

While ABET's vision is to assure quality and stimulate innovation in engineering, technology, and applied science education, the board has incorporated into its mission a commitment to being "responsive and relevant to the needs of the organization and its stakeholders." Among those stakeholders are the companies and agencies that employ the graduates of our nation's engineering programs, and they have expressed increasing interest in written and oral communication skills, as well as concern about the lack of those skills in many technically qualified engineering graduates.

Communication skills, both written and oral, are key to professional success for engineers, and the needed skills go beyond the simple tasks of collecting and compiling data to encompass complex knowledge transfer. In other words, simply amassing data is not sufficient; today's professionals must also be able to interpret and repackage that information for a variety of audiences using a variety of media. The modern engineering student must be not only familiar with the steps and rules of traditional technical writing but also proficient with novel communication media, including the $\mathrm{WebCT}^{2}$ course management system, videoconferencing, email, the Internet, etc. It is critical that engineering students learn how to develop a wellstructured document, presentation, or conversation that communicates the desired message in a manner that is appropriate to the target audience.

Good communication for the engineering professional thus comprises a number of elements,

1 http://www.abet.org

2 WebCT is a privately held company that has developed a course management system for use in the delivery of online education, primarily at the college and university level. The term WebCT is often used to refer to the course delivery system as well as to the company that developed it. 
including the ability to identify a target audience and assess its technical knowledge and information needs; to present factually correct and documented technical content; to organize the information in a way that is clear and meaningful to the reader; and to accomplish all of these goals with writing that is grammatically correct and free of spelling, punctuation, and usage errors.

In response to the new ABET criteria, in 2000, the University of Delaware (UD) Department of Civil and Environmental Engineering (CEE) began collaborating with the Business and Technical Writing Program of the English Department to determine how to enhance written communication within the civil and environmental engineering curricula. The effort resulted in identification of a two-pronged approach: (1) a general attempt to integrate writing into the curriculum during all four years of study; and (2) a specific effort to make the advanced technical writing course more discipline-relevant by piloting a case-based version tailored to civil engineers. The remainder of this paper provides an overview of these two complementary approaches to improving the ability of engineering students to communicate effectively.

\section{Integration of Writing Into Engineering Curricula}

At UD, students in CEE may choose one of two majors, civil engineering or environmental engineering. Students in both majors have traditionally taken three courses that focused on writing or at least incorporated elements of writing: (1) a first-year general English course on critical reading and writing (required for all majors at UD); (2) a technical writing course, usually taken by engineering students in the fourth year; and (3) a fourth-year engineering capstone course that includes a heavy writing component. A major drawback of this program is that it not only offers the students limited opportunities for writing but also clusters these opportunities into the first and fourth years, with virtually no activity in the intervening two years. In addition, because the students usually take the advanced technical writing course concurrently with the capstone engineering course, they are not able to apply the principles taught in the technical writing course to their senior design projects.

In assessing the current curricula in terms of improving communication skills among engineering students, the team realized that while the engineering curricula had little room for the addition of more courses to help develop these skills, integrating writing into actual engineering courses could foster skill development - and perhaps do so even more effectively than dedicated writing courses alone. Integrating writing into the engineering curricula, rather than appending it to the core program, can make the assignments more meaningful and interesting to students while reinforcing the principles of good communication through the use of actual documents and work practices representative of the engineering discipline as it is carried out in private industry and government agencies.

An important goal of the new curricula is to coordinate instruction in communication skills throughout the four years, so that students become increasingly skilled communicators in both 
formal and everyday work contexts. The following outlines how the students' exposure to writing and their opportunity to improve their skills was maximized through the addition of one new course to the curriculum, complemented by minor but meaningful changes to existing courses and the scheduling of these courses.

All students at UD are required to take English 110, Critical Reading and Writing, in the first year. This basic course introduces students to expository and argumentative composition through analysis of selected readings. In addition, specifically for the civil engineering curriculum, writing was integrated into the first-year survey course that introduces students to the profession through guest speakers and non-technical topics. Since the students' technical knowledge is limited at this early stage, the assignments focus on societal aspects of engineering - for example, cultural, aesthetic, and historical issues associated with the structures being discussed.

Formerly slotted for the fourth year, English 410, Technical Writing, is now recommended for second-year students, as it is most effective when delivered as a prerequisite to the capstone fourth-year engineering course. This enables writing aspects to build more cohesively and allows students to begin their senior-design writing projects at a higher level of communicative competency. In addition, both the civil and environmental engineering curricula require students to complete a materials laboratory course during the second year. Like the first-year survey course, this course represented an untapped opportunity for adding writing instruction and practice to the curriculum. The course includes a weekly lecture component to complement the laboratory work. The writing instructor now gives two lectures, one on writing reports, the other on composing tables and figures. Both of these aspects of communication mesh well with the students' course assignments.

Third-year civil and environmental engineering students are now required to take Communication 312, Oral Communication in Business. This course exposes students to the types and principles of communication inherent in the business and professional setting; helps them to develop presentational skills, including analyzing audiences, interviewing, researching, and organizing and delivering information; and provides them with an opportunity to develop and present materials within a variety of group sizes and public contexts.

Finally, for the fourth year, the writing and presentational components of the capstone course (CIEG 410, Senior Design) were enhanced. In addition to being mentored by professional engineers on realistic design projects, student teams now also benefit from a writing instructor who maintains a clear presence with the class. The writing instructor provides formal lectures on proposal and report writing, offers one-on-one assistance with writing projects at the request of students or teams of students, reviews drafts, and offers additional resources for students to use in improving their written and oral presentations. Perhaps the most critical role of the writing instructor is serving on the review and grading panel for the required documents, including a written proposal, an oral presentation, and a final report. Previously, student teams prepared 
proposals and reports with no formal lectures or feedback on writing in terms of formatting, grammar, clarity, organization, etc. Now, they receive formal instruction before carrying out an assignment as well as feedback after completing it. In addition, their oral presentations are videotaped, and they are given the opportunity to review the tapes for feedback on their performance. Thus, the capstone course enables the students to apply what they have learned in both their writing and oral communications courses.

To summarize, then, the writing and oral communication experience has been extended to the full four-year curriculum for civil and environmental engineering as follows:

- First year-freshman English course; writing added to survey course in civil engineering.

- Second year - advanced technical writing course; writing added to lab course in civil and environmental engineering.

- Third year - oral communications course.

- Fourth year - capstone senior design course with extensive written and oral communication requirements.

Although designed at the UD for the civil and environmental engineering curricula, the approach could be easily adapted to the curricula for other engineering disciplines ${ }^{3}$.

\section{Case-Based Technical Writing Course}

According to the UD course catalogue, English 410, Technical Writing, focuses on strategies for structuring and expressing technical concepts and information. Students learn methods for analyzing audiences in scientific research organizations, industry, and government and develop techniques for meeting these readers' needs through documents. Writing is looked at as a problem-solving process that parallels the problem-solving strategies of engineers and scientists. In most sections, students use computers to retrieve information, to write and print their assignments, and to create graphics. Students from a variety of science, engineering, and business majors typically take the course at the same time, and the assignments include standardized types of writing such as instructions, project plans, definition papers, persuasive letters, briefing reports, proposals, press releases, and trip reports.

Although these categories are generally representative of the types of writing required in the workplace, they are often disconnected from a realistic content base for the engineering student.

3 A fuller description of these curriculum changes is found in R. J. Bonk, P. T. Imhoff, and A. H-D. Cheng, "Integrating Written Communication Within Engineering Curricula," Journal of Professional Engineering Education and Practice, accepted 2002. 
One way to address this problem is to offer sections of the course targeted to specific majors and using a case-based approach to technical writing. As this paper went to press, a pilot version of such a course was being taught during UD's Winter Session by a civil engineer/project manager with the Delaware Department of Transportation (DelDOT) in collaboration with writing staff in the Department of English at UD. For the pilot version, English 410 was redesigned for alternate delivery during abbreviated winter and summer terms; however, the instruction and materials could be adjusted as needed for the course to fit within the traditional 14-week semester as well.

The goals of the case-based class are to

- create an intense, communication-rich experience for students that simulates what they would encounter in an actual professional work environment;

- provide a diverse set of realistic experiences in communicating technical information to various audiences, ranging from experts to the general public;

- integrate case materials of engineering practice into a full range of speaking and writing activities, including working in teams to learn project management skills; and

- $\quad$ serve as a model that can be used by other instructors and serve as a prototype for the development of similar courses in other subject areas.

The case-based course allows students to work with a set of actual documents and work practices that represent civil engineering within a government agency. Although it is recommended that English 410 be a second-year course, the case materials are appropriate to students from the sophomore level (before extensive specialized coursework) through the senior level (where students are already "socialized" into their disciplines).

For the pilot course, these materials are taken from the public information campaign developed by DelDOT when the north- and south-bound lanes of Interstate 95 through Wilmington, Delaware, were alternately closed for extensive upgrading. This public works project involved a variety of communication activities for numerous purposes to many audiences. Students are working in project teams to develop their own communication strategies and solutions based on documents from the actual project, including press releases, letters, proposals, pavement reports, brochures, and traffic accident reports. All of these materials are either handed out in class or made available on the class Website.

The students are organized into five teams according to areas of expertise - transit, carpooling, alternate routes, community/public involvement, and intelligent transportation systems. Each team is asked to prepare a proposal and a project work plan, including the number of hours estimated and hourly rates, a task list, resumes, a project schedule, and an organizational chart. The exercise mimics what the students would be required to do if they were employed by a consulting firm that was competing for a project. They are also assigned to develop other 
materials such as radio spots and press releases targeted at specific audiences. After completing the assignments, the students are able to compare their team solutions to those actually used by DelDOT during the project.

The course was developed as a face-to-face classroom-based course, but with a strong component of virtual interaction through the Web-CT course management system to facilitate computer-mediated team and full-class communication, access to a library of case documentation, connections to supporting research resources, online meetings in real time, online document development and review, and instructor interaction.

\section{Conclusions and Future Work}

As the pilot case-based course was being taught when this paper went to press, it was not possible to discuss results, student evaluations, or ways to improve the course. It was also not yet possible to compare-in terms of their performance in the capstone course writing assignments - students who took the case-based technical writing course with those who took the traditional English 410 class. Yet another limitation of the proposed approach is that, while tailoring assignments can increase relevance and therefore learning for the students, it is also administratively difficult and perhaps prohibitively costly to offer designated sections of technical writing to specific majors.

However, where resources permit, discipline-dedicated sections of advanced technical writing can be an effective component of a multi-pronged effort to integrate communication instruction and practice into engineering curricula. Minor changes can be effected in existing courses to ensure that students are continuously exposed to the elements of good communication and the opportunity to practice them, with the overall approach being to build each level on the previous one so that students become increasingly competent communicators.

Another area for future investigation is the concept of team teaching sections of advanced technical writing. During the same session that the pilot case-based course was offered at UD, a writing instructor from the English Department offered another section of the traditional English 410 course in the same time slot. Future offerings of this course could capitalize on complementary resources through team teaching, with the English instructor offering expertise in syntax, grammar, and usage, and the industrial or government engineer providing input on content, audience, and presentation. While this approach would require coordination, it would not double the required resources if the two instructors simply took turns offering lectures on their areas of expertise to both sections of the class.

DIANE S. KUKICH is a writer and editor in the University of Delaware Center for Innovative Bridge Engineering. She holds a master's degree in English from UD. 
STEPHEN A. BERNHARDT is Professor and Andrew Kirkpatrick Chair in Writing at the University of Delaware. He holds a Ph.D. in English and Education from the University of Michigan.

PAUL T. IMHOFF is Assistant Professor in the Department of Civil \& Environmental Engineering at the University of Delaware. He earned his Ph.D. at Princeton University in the Department of Civil Engineering and Operations Research.

MICHAEL J. CHAJES is Chair of the Department of Civil \& Environmental Engineering at the University of Delaware. He holds a Ph.D. in Civil Engineering from the University of California-Davis.

MICHAEL PEARLMAN is a supplemental faculty member in the Department of English at the University of Delaware. He earned his M.A. at the University of Delaware in English Literature and Pedagogy.

DARREN M. O'NEILL is a Civil Engineer and Project Manager at the Delaware Department of Transportation. He holds a bachelor's degree in communications form Villanova University and a bachelor's degree in civil engineering from the University of Delaware. 